\title{
Observação do direito e das cidades inteligentes: contribuições para formação de diretrizes jurídicas para políticas públicas no Brasil
}

\author{
Observation of law and smart cities: contributions to the formation of legal guidelines for \\ public policies in Brazil
}

\author{
Fábio Scopel Vanin \\ Centro Universitário da Serra Gaúcha \\ Doutor em Direito \\ Coordenador do Curso de Direito \\ Caxias do Sul - RS - Brasil \\ fabioscopelvanin@outlook.com \\ Janriê Rodrigues Reck \\ Universidade de Santa Cruz do Sul - UNISC \\ Doutor em Direito \\ Professor PPGD UNISC \\ Santa Cruz do Sul - RS - Brasil \\ janriereck@ibest.com.br
}

Resumo: O objetivo do trabalho é identificar, a partir da observação do ambiente, possíveis contribuições para formação de diretrizes jurídicas para as Políticas Públicas de Cidades Inteligentes no Brasil. O trabalho é desenvolvido expondo-se critérios gerais e conceituais da pesquisa, os elementos centrais sobre Cidades Inteligentes, para a partir de uma observação da Nova Agenda Urbana, estudos do BID e da experiência da Espanha, relacionar tais descrições com a programação do direito público no Brasil. Como método para estruturação das ideias, o artigo vale-se da teoria dos sistemas, observando como o conhecimento do ambiente pode ser acoplado ao sistema do direito. Como resultado, verificase que a observação do ambiente, em especial, dos documentos e experiências pesquisadas, contribuem para suprir a ausência de subsídios da programação do Direito no Brasil, apontando diretrizes jurídicas acerca da finalidade, competência e dos meios a serem observados na produção de políticas públicas para Smart Cities.

Palavras-chaves: cidades inteligentes; direito público; teoria dos sistemas; políticas públicas; política urbana.

Abstract: The objective of this work is to identify, from the observation of the environment, possible contributions to the formation of legal guidelines for the Public Policies of Intelligent Cities in Brazil. The work is developed by exposing the general and conceptual criteria of the research, the central elements on Intelligent Cities, from an observation of the New Urban Agenda, BID Studies and the experience of Spain, to relate such descriptions with the programming of public law in Brazil. As a method for structuring ideas, the article is based on systems theory, observing how the knowledge of the environment can be coupled to the system of law. As a result, it is verified that the observation of the environment, especially of the documents and experiences researched, contributes to supply the absence of subsidies of the programming of Law in Brazil, pointing out legal guidelines about the purpose, competence and means to be observed in the production of public policies for Smart Cities.

Keywords: smart cities; public right; systems theory; public policy; urban policy.

\section{Para citar este artigo \\ ABNT NBR 6023:2018}

VANIN, Fábio Scopel; RECK, Janriê Rodrigues. Observação do direito e das cidades inteligentes: contribuições para formação de diretrizes jurídicas para políticas públicas no Brasil. Prisma Jurídico, São Paulo, v. 20, n. 1, p. 57-80, jan./jun. 2021. http://doi.org/10.5585/prismaj.v20n1.17317. 


\section{Introdução}

A utilização da tecnologia e as novas formas de comunicação configuram-se como um dos principais avanços da contemporaneidade, tendo gerado mudanças significativas em diversos setores, sendo um deles a realidade urbana. O uso de aplicativos em telefones móveis, acessos via internet, que visam trazer facilidade no dia a dia das pessoas, tem se tornado uma alternativa para a melhoria na prestação dos serviços públicos urbanos, ampliando cada vez mais o debate entorno das Cidades Inteligentes, ou, Smart Cities.

As repercussões destas mudanças são inúmeras, alcançando as mais diversas Políticas Públicas setoriais, tanto tipicamente locais, quanto de abrangência regional e nacional, muitas relacionadas com o dia a dia e a vida das pessoas na cidade: o planejamento urbano, mobilidade, facilidades no transporte público, novos modais de transporte individual, controle de qualidade da água, do ar e da iluminação pública, surgimento de uma nova indústria 4.0, novas formas de trabalho, são apenas alguns dos exemplos de temas novos, ainda carentes de estudos e enfrentamentos jurídicos.

O movimento já fora percebido por organismos multilaterais, estando o tema das cidades inteligentes previsto na Nova Agenda Urbana, documento da ONU decorrente da Agenda Habitat III, assim como, tem inspirado estudos pelo Banco Interamericano de Desenvolvimento, o BID. Alguns países, como a Espanha, já possuem planos nacionais e uma estratégia clara de como direcionar este movimento em favor da população e do desenvolvimento socioeconômico.

É com base nesta realidade de carência de regulamentos e reflexões jurídicas sobre o tema das cidades inteligentes no país, somada com a proliferação de práticas e o avanço do debate nos organismos internacionais, que se apresenta o presente artigo. O objetivo é identificar, a partir da observação do ambiente, possíveis contribuições para formatação de diretrizes jurídicas para as Políticas Públicas de cidades inteligentes no Brasil.

Valendo-se do repertório conceitual da teoria dos sistemas para definição dos seus critérios, o ensaio tem como elemento central o seguinte problema: Em que medida a observação dos documentos e debates das agências internacionais, assim como, de experiências práticas de países como a Espanha, pode contribuir com a formatação de diretrizes jurídicas para as Políticas Públicas de cidades inteligentes no Brasil?

A hipótese é de que tais reflexões e práticas contribuem no esclarecimento dos desafios que envolvem a atuação governamental com enfoque nas cidades inteligentes, trazendo consigo 
elementos que auxiliam na definição de diretrizes jurídicas, como a competência, finalidade e os meios a serem observados na produção de Políticas Públicas de Smart Cities.

Confirmando ou não tal hipótese, o presente estudo justifica-se ao contribuir com a construção de reflexões, que podem ser vistas como alternativas para as decisões a serem tomadas na definição de diretrizes jurídicas mais estáveis para as Políticas Públicas de Smart Cities no Brasil. Pretende-se de alguma forma evidenciar tema que surge com muita força e inúmeras interrogações, sendo necessária sua exploração para a construção de respostas que sejam convergentes com a programação do direito brasileiro em vigor, em especial relacionadas ao direito público.

\section{Critérios para a construção de diretrizes jurídicas para cidades inteligentes no Brasil}

Não há uma unidade conceitual para as Smart Cities. Trata-se de um tema inserido em um cenário de contingência, com amplas possibilidades. Guimarães e Xavier (2016, p. 13631364) apresentam o assunto como integrante da cultura contemporânea, contendo múltiplas interpretações. Os autores destacam a importância do seu aprofundamento em estudos jurídicos e indicam que o tema envolve questões de "Estado, mercado, sociedade civil, parcerias públicoprivadas, participação popular, governança, accountability”, entre outros.

Neste sentido, o artigo irá abordar um tema novo, complexo e com múltiplas facetas, o que exige um repertório conceitual que responda a este dinamismo contemporâneo. A matriz teórica deste artigo é a teoria sistêmica. De acordo com ela, o Direito não segue uma lógica mecanicista, a partir de conceitos dados, mas sim, passa a ser construído a partir de distinções, que decidem por uma alternativa, entre várias disponíveis. Segundo Reck e Bitencourt (2016, p. 139), com base nesta teoria, "toda solução ou estado de fato e de direito, além de provisória, é uma escolha entre outras no tempo".

Neste trabalho, a política pública será observada como "um conceito aberto, e por deveras complexo", conforme indicado por Reck e Bitencourt (2016, p. 136). Com base no conceito dos autores a Política Pública deve ser observada como "um conjunto de ações e programas continuados no tempo, que afetam simultaneamente várias dimensões básicas da vida de uma população", devendo estar organizada em uma determinada área e explicitar suas "diretrizes e objetivos numa sucessão de atos que se desenvolvem na busca de um fim determinado, posto".

Uma política pública, portanto, relaciona-se com a atuação do Poder Público, com vista a alcançar objetivos previstos em normas jurídicas. Para promovê-la, o Estado se vale de diversos instrumentos típicos de Direito Administrativo: serviços públicos, fomento, poder de 
polícia, intervenção do Estado na propriedade, entre outros. Refletir sobre diretrizes de uma política pública - como pretende este artigo - significa identificar quais reformas podem e devem ser feitas nestes mecanismos, tendo em vista que um novo objetivo será colocado, com enfoque em cidades e tecnologia.

Desta forma, pretende-se explorar a contingência - múltiplas alternativas - para possibilitar o "aumento da capacidade de análise" e produzir decisões qualificadas, que contribuam na construção de diretrizes jurídicas. Assim como em outras áreas, na ação governamental de Smart Cities, “o gestor de políticas públicas terá de pensar por que uma determinada sequência de ações aconteceu em detrimento de outras possíveis", ou seja, decidir entre diferentes opções disponíveis. (RECK, BITENCOURT, 2016, p. 136)

O trabalho faz escolhas, entre diversas alternativas, ao indicar diretrizes jurídicas para as Políticas Públicas de cidades inteligentes. Desta maneira, não é pretensão deste artigo apresentar um conceito jurídico ou determinações definitivas. A ideia é apontar reflexões sobre a competência, a finalidade e os meios a serem empregados nas ações governamentais com enfoque nas cidades inteligentes, como forma de contribuir com o debate jurídico sobre o tema, que ainda é incipiente nesta área do conhecimento.

Observando-se a programação e a estrutura do sistema do direito no Brasil verifica-se inexistir lei, decisão judicial significativa, ou ainda, doutrina jurídica definitiva e relevante que torne clara e redundante quais são as diretrizes jurídicas para as Políticas Públicas de Smart Cities. Na perspectiva sistêmica, pode-se dizer que, se existe informação, ela ainda não gera comunicação no sistema do Direito. Ainda que se considere a existência de comunicação, ela não tem potencial para estabilizar os conteúdos envolvidos, o que torna relevante a realização de estudos, com o objetivo de construir melhores perspectivas, diminuir a complexidade, apresentar alternativas e qualificar decisões.

Com base nas percepções de Reck (2009, p. 33) conceitos "são operações condensadas no sistema jurídico em forma de estruturas, e são constantemente utilizadas para a orientação da ação e solução de casos". Uma das funções, ao criar-se um conceito jurídico, é reduzir a complexidade de um tema e tornar objetivas as explicações, facilitado a compreensão de algo em um contexto geral, e, ao mesmo tempo, dar espaço para a criação de novas complexidades e um novo aprofundamento do tema. Ainda com base no autor, ao desenvolver-se um conceito dentro do sistema do direito permite-se "a identificação de novas alternativas, mas que se enlaçam no sistema enquanto natureza jurídica”, como se pretende este ensaio.

Ao mesmo tempo em que o sistema do direito no Brasil apresenta reduzida informação sobre Smart Cities, o que dificulta de sobremaneira a formação de comunicação e a observação 
a partir de conceitos jurídicos já dados, observa-se que há no ambiente - fora do sistema - um conhecimento que parece interessar ao sistema do direito, podendo por ele ser selecionado, tendo como base os seus meios.

Com base na teoria base adotada, essa observação que o sistema do Direito faz do ambiente pode ser selecionada através do mecanismo denominado acoplamento estrutural ${ }^{1}$, que permite, entre outras finalidades, que o sistema do direito evolua, passando a gerar novas comunicações que até então não integravam sua memória. Assim, segundo Luhmann (2016, p. 589-590) é através dos acoplamentos estruturais que "o sistema supõe determinadas características de seu ambiente, nele confiando estruturalmente”, para a partir daí, incluir (acoplando) ou excluir (não acoplando) novas estruturas, como neste caso, aspectos relacionados as Smart Cities.

Desta forma, o presente estudo visa enumerar elementos que contribuam com a construção de diretrizes jurídicas para Políticas Públicas de Smart Cities no Brasil valendo-se do que Luhannn (2016, p. 527) chama de argumentos substanciais, ou ainda, de interesses, que são elementos buscados fora do sistema do direito para a construção de prescrições que passem a integrar sua estrutura e memória. Nas palavras do autor "o sistema jurídico constrói sua versão do interesse do ambiente no sistema do direito". Em outras palavras o artigo buscará, a partir de elementos de outras ciências, construir elementos que possibilitem a tomada de diferentes decisões jurídicas.

Neste sentido, tendo como base a teoria dos sistemas, o conhecimento de Smart Cities que existe no ambiente - fora do sistema - não pode ser simplesmente integrado ao sistema do direito de maneira imediata, sem critérios. Luhmann (2016, p. 596) destaca uma questão fundamental, a de que "os acoplamentos estruturais jamais introduzem normas do ambiente do sistema, só fazem provocar irritação" nos sistemas parciais, como o Direito.

O fato de existir uma "pressão do ambiente social" por uma definição do sistema do direito, pode fazer com que ele inclua algo sem observar seu código, o que corrompe e deforma o sistema, causando o que o autor chama de corrupção sistêmica. Em outras palavras, para a construção de um conceito de Smart Cities no sistema do direito, mais especificamente, brasileiro, se faz necessário sua confrontação com a programação vigente que afeta a matéria leis, decisões judiciais, regulamentos em vigor - sob pena de incidir nos problemas descritos.

\footnotetext{
${ }^{1} \mathrm{O}$ autor observa o sistema do direito, como um sistema cognitivamente aberto e operativamente fechado, tendo uma função e um código próprios que lhe dão sentido e que não são utilizados em nenhum outro sistema e nem no seu contato com o ambiente. Assim, tal fechamento, segundo Luhmann refere-se somente as atividades internas do sistema, mas não quer dizer que não seja possível uma comunicação do sistema com o ambiente. Essa relação se dá através de mecanismos específicos, como o acoplamento estrutural.
} 
Destacados os critérios de ordem teórica, o trabalho se propõe a observar dois cenários: as reflexões das agências internacionais acerca do tema das Smart Cities; e a experiência da Espanha, tendo como base o Plano Nacional e alguns estudos jurídicos desenvolvidos naquele país sobre o tema. Feito isso, serão confrontadas as observações com a programação do direito brasileiro. As diretrizes serão apresentadas em três grupos: finalidade, competência e meios a serem observados na construção de Políticas Públicas.

O resultado que se espera do estudo relaciona-se com o conceito de evolução, proposto por Luhmann (2016, p. 323). Para o autor, evolução não está relacionada com um avanço temporal, nem como uma hipotética busca por um ideal, mas sim, na forma como direito muda, através dos mecanismos evolutivos da variação, seleção e estabilização, se distinguindo do ambiente, por sua operação, estrutura e programação próprias. ${ }^{2}$

Os elementos observados nos capítulos a seguir - debates das agências internacionais e experiência da Espanha - serão tomados como mecanismos de variação para o sistema do direito, sendo selecionadas algumas sugestões de diretrizes, a partir da programação interna do direito brasileiro. Ao final, não se buscará descrever um conjunto de orientações definitivas, mas reflexões jurídicas que auxiliem no direcionamento das Políticas Públicas de Smart Cities no Brasil.

Assim, considera-se que a estabilização dos elementos a serem apresentados serão meramente parciais. Uma estabilização mais definitiva das diretrizes jurídicas apontadas neste trabalho depende de outros fatores, em especial decisões a serem tomadas por organizações, que somente se efetivam ao gerar redundância em outros textos jurídicos, normas legais e decisões judiciais, preferencialmente, de maneira reiterada. (RECK, 2009, p. 23) ${ }^{3}$

\section{Aspectos jurídicos básicos para as políticas públicas para cidades inteligentes}

O tema das cidades inteligentes remete para a ideia do uso de tecnologia no âmbito dos Municípios. Marquina (2017, p. 08) destaca a utilização dos TIC (Tecnologia de informação e comunicação) como algo que não deve ser ignorado, mas aproveitado na perspectiva urbana, sendo muito útil para melhorar "la eficiencia y la innovación, facilitando la integración de los servicios municipales, la cooperación entre sectores y como ayuda en la toma de decisiones en las áreas clave” que compreendem o desenvolvimento das cidades.

\footnotetext{
${ }^{2}$ Para uma abordagem da evolução do sistema do direito, na perspectiva sistêmica, e observando o Direito e o Urbanismo, destaca-se o estudo de Vanin (2020, p. 36-50), onde tais conceitos são apresentados de forma detalhada.

${ }^{3}$ Neste contexto, Reck destaca que um conceito pode passar a ser aceito no sistema jurídico não só por critérios relacionados ao rigor científico, mas por situações subjetivas como são os "mecanismos de reputação", que tomam como base situações empíricas como o acesso a editoras, prestígio profissional, amizades com figuras-chave, citação em decisões jurisprudenciais, entre outros.
} 
Já se forma certo consenso que não é a simples utilização de tecnologia que dará aos municípios a condição de "inteligentes", sendo necessário a atenção de outros preceitos para alcançar tal condição. Os autores Guimarães e Xavier (2016, p. 1.364) destacam que a "literatura estrangeira explora bastante o termo smart city, relacionando-o ao urbanismo contemporâneo e alguns de seus fenômenos culturais" estando fundado não só no uso de tecnologia, mas na atenção ao meio ambiente e em aspectos do desenvolvimento humano e social, que toma como base uma tríade de princípios: questões ambientais; a inovação tecnológica e comunicação digital; e o desenvolvimento.

No mesmo sentido, compreendendo que a ideia de cidades inteligentes extrapola o simples uso da tecnologia, em artigo que relaciona as Smart Cities com os preceitos Direito à Cidade, Guimarães e Araujo (2018, p. 1.797) destacam que o conceito abrange um "alinhamento da perspectiva das cidades inteligentes ao desenvolvimento das funções sociais da cidade na busca de uma convergência entre ambas", reforçando a compreensão de que a tecnologia deve ser utilizada para o alcance de um desenvolvimento mais humano. ${ }^{4}$

Retomando as ideias de Marquina (2017, p.08) verifica-se que o autor também dá ênfase para esta questão, ao afirmar que "lo que conferirá a una ciudad de "inteligencia" no será mera inversión en tecnología, ni la apuesta por la transformación digital de su administración, sino su integración real”. Desta forma, o autor destaca que a utilização da tecnologia é um meio, que tem como finalidade, fazer mais felizes as pessoas e mais prosperas as comunidades.

Observando-se a programação do direito brasileiro, no que diz respeito a Política Urbana, verifica-se que as ideias convergem com o texto legal. Seu objetivo, segundo o art. 182 da CF é "ordenar pleno desenvolvimento das funções sociais da cidade e garantir o bem-estar de seus habitantes". Desta forma, uma ação de tecnologia aplicada a cidade, na perspectiva da política urbana, deve ter esta finalidade, sob pena de não ser reconhecida pelo direito. ${ }^{5}$

Os autores Guimarães e Xavier (2016, p. 1.366) relacionam o consenso acerca dos critérios socioambientais das cidades inteligentes, com a diretriz das cidades sustentáveis, prevista no art. $2^{\circ}$, I do Estatuto da Cidade, entendendo que tal visão decorre de uma "combinação de estatutos diversificados no direito brasileiro mediante a base constitucional integrativa" e que por respaldar uma "proteção ampla desse novo fenômeno urbano".

Tais reflexões reforçam que, a partir de uma observação jurídica, para que possuam respaldo da Política Urbana no Brasil, as Políticas Públicas de cidades inteligentes devam ter

\footnotetext{
${ }^{4}$ Os autores observam que uso de tecnologias compreende "o envolvimento dos cidadãos no processo de inovação urbana" enquanto o Direito à Cidade mantém a atenção para a combate e a redução das desigualdades sociais e territoriais, eliminação da pobreza, promoção da justiça social e a satisfação dos direitos fundamentais das pessoas de terem condições de vida digna.

${ }^{5}$ Sobre o tema, destaca-se estudo de Reck e Vanin (2020) que aprofunda o tema das Cidades Inteligentes e a sua relação com Política Pública Urbanística em específico.
} 
como fim os objetivos previstos no art. 182 da Constituição e como meio as diretrizes previstas no Estatuto da Cidade. ${ }^{6}$ As orientações programadas pelo Direito apontam para questões de sustentabilidade, oferta de equipamentos urbanos e comunitários, justa distribuição dos benefícios e ônus decorrentes do processo de urbanização, entre outros.

A reflexão pode ser mais ampla, observando o uso de tecnologia na promoção de Políticas Públicas em cidades inteligentes não só na perspectiva da Política Urbana, mas de outras áreas, onde a ação governamental deve ser observada na perspectiva do Direito Público como um todo. Entende-se que neste caso as diretrizes jurídicas para Políticas Públicas de Smart Cities devam ter em conta aspectos materiais de preocupação com bem-estar e desenvolvimento, não tendo respaldo no Direito o mero uso da tecnologia pela tecnologia ou em prejuízo para a coletividade.

A ideia chave que norteia o direito público é o interesse público. Para Mateo e Sanchez (2012, p. 75) a administração pública deve estar "fundamentalmente preocupada por la realización del interés público”, sendo a pedra de toque para analisar as relações entre ação do governo e justiça. Importante a ressalva, que não se toma interesse público como algo que possa ser compreendido como um conceito dado. Reck e Bitencourt (2016, p. 136), destacam seu caráter a priori abstrato, afirmando que ele pode ser identificado e definido mediante um procedimento democrático. No mesmo sentido Garcia de Enterría e Fernanández (2013, p. 120) destacam o papel especial do interesse público como "idea rectora básica de la actuación de la Administración".

Neste contexto, não se pode aceitar, a partir de uma observação jurídica, um conceito de cidade inteligente que não traga consigo o interesse público como preocupação última de ação governamental, o que tem relação direta com um agir do Estado em benefício da coletividade. No mesmo sentido, de observância básica, são os princípios constitucionais da legalidade, impessoalidade, moralidade, publicidade e eficiência, indispensáveis na execução de qualquer ação pública.

Desta forma, os primeiros elementos centrais que devem estar presentes na construção de diretrizes jurídicas de Smart Cities para o Brasil, são os seguintes:

Finalidade/objetivo: em qualquer ação governamental, o interesse público deve estar presente, e, em se tratando de medidas relacionadas com a Política Urbana, as políticas públicas devem

\footnotetext{
${ }^{6}$ Vanin $(2015$, p. 94) e Leal (2010, p. 136) consideram que as diretrizes do Estatuto da Cidade têm efeito vinculante. Vanin destaca que as diretrizes devem ser compreendidas como um caminho a ser seguido, para que sejam atingidos os objetivos da Política Urbana. Já Leal, argumenta que as diretrizes representam "verdadeiras opções políticas fundamentais do legislador e da comunidade nacional" sendo de observância obrigatória.
} 
ter como foco a ordenação do pleno desenvolvimento das funções sociais da cidade e a garantia o bem-estar dos habitantes.

Meios a serem observados: as políticas públicas de cidade inteligente devem atentar aos princípios da administração pública, e nas ações de governo com enfoque na Política Urbana, para as diretrizes do Estatuto da Cidade na construção das soluções inteligentes.

Fica evidente que não é o mero uso de tecnologia no espaço urbano que promove ao município o atributo de inteligente na perspectiva do Direito. Tal condição vincula-se a utilização de TICs, desde que, de acordo com os meios e objetivos previstos na programação jurídica, como pode ser percebido nas reflexões apresentadas nos próximos tópicos.

\section{Diretrizes de cidade inteligente: as percepções das agências internacionais}

Destacados alguns aspectos jurídicos básicos que alcançariam o tema das Smart Cities no Brasil, em especial, a atenção ao interesse público e os princípios da administração pública, e ainda, objetivos e diretrizes da política urbana, passa-se a descrever alguns conceitos bases decorrentes de debates advindos nas agências internacionais, que podem contribuir com novas especificações ao presente estudo.

O ponto de partida é observar como a Nova Agenda Urbana, documento da ONU decorrente dos debates da Habitat III trata as cidades inteligentes. O documento traz o assunto no item 66 da "Declaração de Quito sobre cidades e aglomerados urbanos para todos", o qual segue transcrito:

66. Comprometemo-nos a adotar uma abordagem de "cidade inteligente", que faça uso de oportunidades de digitalização, energia e tecnologias limpas, assim como de tecnologias de transporte inovadoras, proporcionando consequentemente alternativas para os habitantes tomarem escolhas mais amigáveis ao ambiente e impulsionarem o crescimento económico sustentável, permitindo que as cidades melhorem a sua prestação de serviços. (ONU, 2016)

Verifica-se que o conceito trabalhado a partir da Nova Agenda Urbana, considera inteligente o uso de "energia e tecnologia limpas" e de transporte inovador, direcionando o seu uso em três eixos: a participação dos cidadãos, dando enfoque para um acesso à informação de qualidade, que possibilite escolhas individuais atentas com a sustentabilidade ambiental; uma melhora da economia; e uma melhor prestação de serviços pelos governos.

Tal indicação já abre um debate jurídico muito significativo em nível de Brasil. Observando-se a programação do direito brasileiro, percebe-se que o tema cidades inteligentes, extrapola, e muito, os aspectos de política urbana, ou ainda, de tecnologia ou de interesse local, abrindo grande margem para problemas de competência. 
Conforme dispõe Reck (2018, p. 47) "a função da competência é diminuir a complexidade de opções de uma decisão a ser tomada a partir do Direito por um órgão ou agente", neste sentindo, quando de define competência, uma unidade de governo "se desonera de ter que decidir sobre tudo". Com a redução de complexidade, ganha-se efetividade, possibilitando que um determinado órgão se especialize e decida sobre temas específicos. Analisar as Smart Cities e políticas públicas municipais implica no exame das competências dos entes federativos no Brasil.

Importante ressaltar, que a abordagem da ação governamental em Smart Cities é um caso em que fica evidenciado o conceito de "policompetência". Com base nele, Reck e Bittencourt (2016, p. 143) destacam ser necessário "o abandono do ideal de especialização absoluta”, vez que embora as políticas sempre sejam setoriais e tematizadas - como no caso, cidades inteligentes - suas disposições “devem ser flexíveis e contar com mecanismos tais que permitam lidar com mais de uma competência social”,

Neste sentido, como exemplo, podem ser citados os serviços de telecomunicação e uso de dados. Ainda que observados no âmbito das cidades, dependem de definições em nível federal, por força do art. 21, XI da CF/1988. De igual maneira a possiblidade de transporte inovador, que demanda uma análise própria, com observância na norma que trata da Política Nacional de Mobilidade Urbana, Lei n. 12.587/2012.

O direcionamento das políticas previstas na Nova Agenda Urbana para cidades inteligentes também acaba por criar demasiada dificuldade no contexto de competência vigente no país. Grande parte das ações, para serem implementadas, dependem de um alinhamento entre as diversas esfera de governo, podendo gerar problemas de conflito de atribuições.

O conceito apresentado pela ONU, observado na perspectiva da programação do direito no Brasil, desperta para uma dificuldade de definir a qual ente caberia o que em uma implementação de Políticas Públicas voltadas para as Smart Cities, o que reforça a ideia de policompetência como algo relevante. Reck e Bittencourt (2016, p. 143) ressaltam, entre outras vantagens, que tal visão contribui para utilizar "mais eficientemente os parcos recursos públicos, evitando repetições e tensionando as estruturas".

A outro documento importante da ONU, fundamental para a inclusão do tema na Nova Agenda Urbana, decorre da realização de debates anteriores a sua publicação, registrados como "Documentos Temáticos" da Habitat III (ONU, 2015). A questão específica das cidades inteligentes está descrita no relatório de número 21 , no qual foram apresentados uma série de 
conceitos $^{7}$, que culminaram na formação de um documento específico sobre o assunto, que tem o seguinte resumo executivo:

\begin{abstract}
O papel das TICs em um contexto de urbanização interligada e o dinamismo das cidades no século XXI está sendo cada vez mais compreendido. As TICs trouxeram mudanças significativas e irrevogáveis à forma como as pessoas vivem, estimularam prosperidade social, e tiveram impacto considerável no crescimento e competitividade das economias e cidades. Também é cada vez mais reconhecido o potencial das TICs para atingir os resultados desejados em desenvolvimento urbano: espaços públicos de alta qualidade, redes bem conectadas, densidade bem desenhada, maior eficiência de recursos, melhoria na qualidade de vida, crescimento com emissões de carbono reduzidas, e criação e gerenciamento de conhecimento que lida com necessidades e riscos - os contornos de cidades que são inteligentes e sustentáveis. (ONU, 2015).
\end{abstract}

Desta forma, a visão das Nações Unidas pode sobre cidades inteligentes, pode ser complementada pelos seguintes aspectos: ser um campo em construção; apresentar-se como um caminho sem volta; que representa uma contribuição com a prosperidade social e a competitividade das comunidades locais; que possui relação com a melhoria dos espaços públicos urbanos, com a utilização de recursos e o gerenciamento de riscos.

Do ponto de vista conceitual, verifica-se que a visão da ONU converge com as normas de direito público e política urbana descritas no tópico anterior, vez que, se reconhece que o uso de tecnologia, na maioria dos casos, tem gerado resultados significativos na melhoria da qualidade de vida, agregando espaços públicos de qualidade, entre outros.

Relacionando a descrição do documento temático com a questão da competência, percebe-se que ele traz em definitivo os temas meio ambiente, competitividade econômica, melhoria de espaços públicos e controle de riscos, confirmando que, embora trate de tema de enfoque final eminentemente local, sua execução e legislação, em decorrência da multidisciplinaridade, deverá envolver o exercício de diferentes competências pelos três entes federativos.

Destaca-se ainda que a ONU trata o assunto como um caminho "irrevogável”, ficando um sinal de alerta quanto a ausência de uma expansão na programação do direito com esta finalidade no Brasil, visto ser indispensável, em decorrência do princípio da legalidade, legislações que permitam e incentivem novas iniciativas neste sentido no país.

Embora não represente a posição oficial da entidade, um estudo do BID, realizado por Bouskela e Casseb (2016, p. 32-34) pode também contribuir com a proposta deste trabalho.

\footnotetext{
${ }^{7} \mathrm{O}$ próprio documento da ONU reconhece a existência de inúmeras definições e abordagens para o tema, dando destaque para três grupos conceituais: (1) o que observar as cidades inteligentes como aquelas que "possuem infraestrutura física, social, institucional e econômica "inteligentes", garantindo simultaneamente centralidade dos cidadãos em um ambiente sustentável"; (2) conceitos que tratam de "características-chave definidas por fatores distintos (por exemplo, economia inteligente, mobilidade inteligente, pessoas inteligentes, ambiente inteligente, vida inteligente, governança inteligente)"; (3) e ainda, aquelas definições que "focam no uso estratégico de novas tecnologias e abordagens inovadoras para melhorar a eficiência e competitividade das cidades".
} 
Nela, são apresentados quatro focos importantes para uma Smart Cities: (1) ser sustentável, e, assim se utilizar da tecnologia digital "para reduz ir os custos e otimizar o consumo de recursos de modo que sua administração presente não comprometa o uso pelas gerações futuras"; (2) ser inclusiva e transparente, possuindo "canais de comunicação diretos com os cidadãos" e operando com dados abertos, em especial em finanças; (3) gerar riqueza, oferecendo "infraestrutura adequada para geração de empregos de alta qualidade", assim como, possibilitando "competitividade e crescimento dos negócios"; e tem enfoque nos cidadãos; (4) usar a tecnologia "para melhorar a qualidade de vida das pessoas e dar acesso rápido a serviços públicos mais eficientes". O estudo apresenta em destaque o seguinte conceito:

Uma Cidade Inteligente é aquela que coloca as pessoas no centro do desenvolvimento, incorpora tecnologias da informação e comunicação na gestão urbana e utiliza esses elementos como ferramentas que estimulam a formação de um governo eficiente, que engloba o planejamento colaborativo e a participação cidadã. Smart Cities favorecem o desenvolvimento integrado e sustentável tornando-se mais inovadoras, competitivas, atrativas e resilientes, melhorando vidas.

As reflexões dos autores, em obra que elenca inúmeras experiências bem-sucedidas, traz outros elementos que podem ser adicionados aos aspectos indicados pela ONU nos debates da Habitat III, ao reforçar o papel central do cidadão no processo, em especial, destacando a potencialidade dos TIC para a transparência na ação governamental e no compartilhamento de dados. As formas de participação através de destes mecanismos de tecnologia, assim como, o debate sobre em que nível de transparência deve se dar na publicidade de dados são temas jurídicos centrais, sendo elementos importantes na construção de diretrizes para Políticas Públicas de Smart Cities para o Brasil.

As formas de participação por meio de TICS no Brasil são trabalhadas por Guimarães e Araujo (2018, p. 1.807), e, embora destaquem existir uma crítica no uso destes mecanismos, em especial em decorrência da tecnologia e do acesso à internet não estar ao alcance de todos, perceberam em seu estudo "que o uso de ferramentas digitais diminui os custos e otimiza o tempo daqueles que participam de algum processo deliberativo", assim como promovem "uma espécie de aproximação entre os interlocutores, criando novos canais entre os cidadãos e organizações da sociedade civil ou entre cidadãos e as próprias autoridades políticas", o que influencia na elaboração de políticas públicas.

Relativo à proteção de dados, alguns estudos europeus têm apresentado severas preocupações quanto a preservação da privacidade dos cidadão em um ambiente de compartilhamento de dados. Sobre o tema, Mañas (2017, p. 31) destaca que transparência e privacidade eram temas que até pouco tempo estavam fora do debate jurídico, mas hoje são 
imprescindíveis para o desenvolvimento da sociedade, em especial para as cidades inteligentes, sendo ponto chave, que exige debate entre técnicos e juristas. As ações devem equilibrar acesso aos dados para implementação das novas tecnologias e proteção da intimidade. ${ }^{8}$

Assim, tendo em vista os apontamentos da ONU e dos estudos do BID, confrontados com a programação do Direito no Brasil, contribui na construção com dois novos elementos:

Competência: políticas públicas que evolvem Smart Cities caracterizam-se por envolver um vasto grupo de assuntos, em um cenário de policompetência, não se limitando às ações de política urbana ou tecnologia, existindo deveres e possibilidades de ação dos três níveis de governo.

Meios a serem observados: as ações de interesse público, em especial relacionadas a utilização de dados, não devem afetar o direito a intimidade do cidadão, não podendo a necessidade de compartilhamento prejudicar tal direito do cidadão.

Desta forma, a definição do papel de cada ente federativo para as Política Públicas de Smart Cities é uma questão em aberto, envolvendo elementos complexos de competência material e formal, que merecem o aprofundamento em outros estudos. A outra diretriz enfatiza o equilíbrio transparência governamental - compartilhamento público de dados - e segurança dos dados individuais. Políticas Públicas de cidades inteligentes tendem a tornar públicos dados individuais, devendo isto ocorrer sem prejuízo ao direito de privacidade das pessoas, em respeito ao disposto no art. $5^{\circ}$ incisos X e XII da Constituição Federal de 1988 e a Lei Geral de Proteção de Dados (LGPD).

\section{Contribuições da Espanha nos desafios jurídicos para cidades inteligentes no Brasil}

Ao lado da visão da ONU e dos estudos do BID, verifica-se que a experiência da Espanha também pode contribuir na busca dos elementos que vem sendo construídos neste estudo. O país europeu, que é referência em outras práticas de urbanismo, conforme pode ser observado na obra de Borja e Muxi (2009) ${ }^{9}$, já possui uma ação estruturada, baseada no Plano Nacional de cidades inteligentes, que vigora desde 2015. O documento traz no seu texto o seguinte objetivo central:

\footnotetext{
${ }^{8} \mathrm{O}$ tema no Brasil está regulamentando na Lei Geral de Proteção de Dados (LGPD). Um estudo que aborda os aspectos constitucionais da proteção de dados pessoais, já com atenção ao julgamento da ADI 6.387 é de Fonseca (2021).

9 A obra "Urbanismo en el siglo XXI" tras iniciativas de planos parciais e de recuperação de áreas que tornaram cidades como, Bilbao, Madrid, Valencia, Barcelona, entre outras, modelos em avanços urbanísticos.
} 
Contribuir al desarrollo económico, maximizando el impacto de las políticas públicas en TIC para mejorar la productividad y la competitividad, y transformar y modernizar la economía y sociedad española mediante un uso eficaz e intensivo de las TIC por la ciudadanía, empresas y administraciones. (ESPANHA, 2015, p. 16).

Verifica-se que objetivo chave do governo da Espanha é um avanço na indústria nacional de TIC que tenha como finalidade melhorar as políticas públicas locais, ou ainda, que o avanço da indústria de tecnologia resulte em avanços para a cidadania, empresas e administrações, como enfoque nas cidades espanholas ${ }^{10}$. A melhoria da qualidade de vida das comunidades é vista como uma consequência da implantação do Plano. Reforça esta visão, o fato de que boa parte da argumentação em favor do uso de tecnologia para as comunidades locais tem um enfoque de transformá-las em atrativos turísticos, gerando um interesse de visitação, inclusive com a descrição do conceito de "destino turístico inteligente" 11 . (ESPANHA, 2015, p. 17)

Melhorias na qualidade ambiental são somente tangenciadas no documento, como um resultado esperado em decorrência da adoção do modelo inteligente, com destaque para o indicativo de mudança dos modais de transporte, que reduziriam a emissão de gases. A mobilidade é um tema em destaque na proposta, tanto no que diz respeito para a acessibilidade universal, quanto para melhorias relacionadas a redução de congestionamentos, ferramentas que informem os usuários em tempo real as condições de tráfego e nas melhorias que impulsionem o transporte público.

Assim, são apresentados os quatro objetivos específicos do governo espanhol, no Programa Nacional de cidades inteligentes, que podem ser resumidos da seguinte forma: (1) Fortalecimento na produtividade e competitividade da Industria da TICs; (2) Eficiência dos serviços públicos prestados pelas comunidades locais, com mecanismos que auxiliem as cidades a adotar tais tecnologias, assim como, para que se tornem destinos turísticos inteligentes; (3) Governança do Sistema de cidades inteligentes, com a criação de um rede de fluxo de informações; (4) Estandardização e regulamentação dos modelos de tecnologias a serem utilizados, facilitando o acesso.

Percebe-se que na Espanha já há demasiada redução de complexidade na regulamentação do tema, estando claro o caminho escolhido pelo país na adoção e no incentivo

\footnotetext{
${ }^{10}$ A visão fica ainda mais clara, pela seguinte afirmação contida no Plano: “el Fortalecimiento del Sector Industrial, como vertebrador del conjunto de acciones de gobierno necesarias para conseguir, a través del subsector industrial TIC, mejorar la aportación de éste al PIB Nacional, ayudando a incrementar la eficacia y la eficiencia con la que se prestan los servicios públicos en las entidades locales a ciudadanos, empresas y turistas. Todo lo cual conllevará una mejora en la calidad de vida de los pueblos y ciudades españolas, y repercutirá en el crecimiento económico".

${ }^{11}$ Conceito de "destino turístico inteligente: "Un destino turístico innovador, consolidado sobre una infraestructura tecnológica de vanguardia, que garantiza el desarrollo sostenible del territorio turístico, accesible para todos, que facilita la interacción y la integración del visitante con el entorno e incrementa la calidad de su experiencia en el destino y mejora la calidad de vida de los residentes".
} 
as práticas de Cidade Inteligente pelas comunidades locais. É verificado inclusive, a forte intenção do governo espanhol em nacionalizar as melhores práticas, em especial através de um processo de regulamentação em construção. Ademais, o plano apresenta um financiamento claro e detalhado, onde consta um investimento de 190 milhões de Euros, já direcionado, de maneira específica, para a cada um dos 5 eixos do programa. ${ }^{12}$ (ESPANHA, 2015).

Como forma de trazer elementos que contribuam na construção de diretrizes jurídicas para Políticas Públicas de cidades inteligentes no Brasil, cabe destacar o resultado da implementação do eixo "facilitar a las ciudades el proceso de transformación hacia una ciudad inteligente" que integra o programa espanhol. Entre os seus objetivos, está a estipulação de normativas técnicas para estandardização do tema, que têm sido emitidas pelas AENOR, uma associação espanhola dedicada a certificação de atividades.

Segundo Ojeda (2017, p. 87-88) já existem mais de 15 normativas emitidas, relacionadas a cidades inteligentes, que tratam dos mais diferentes temas: rede de águas, de celulares e telecomunicação; indicadores de qualidade para serviços urbanos e qualidade de vida; dados abertos, etc. Uma delas, a Norma UNE 178201:2016, merece destaque neste trabalho, pois indica um conceito de Smart Cities:

Una ciudad inteligente es una ciudad justa y equitativa, centrada en el ciudadano, que mejora continuamente su sustentabilidad y resiliencia aprovechando el conocimiento y los recursos disponibles - especialmente las Tecnologías de la Información y la Comunicación (TIC) - para mejorar la calidad de vida, la eficiencia de los servicios urbanos, la innovación y la competitividad, sin comprometer las necesidades futuras en aspectos económicos, de gobernanza, sociales y ambientales. (ESPANHA, 2016).

Verifica-se que o conceito advindo das normativa da Espanha demonstra-se bastante abrangente, contendo os elementos centrais indicados na observação das normativas na ONU e do estudo do BID, em especial: o papel central do cidadão; preocupação com os aspectos de sustentabilidade; aproveitamento dos potenciais das TIC; preocupação com a qualidade de vida; tornar eficientes os serviços públicos urbanos; melhoria na competitividade econômica e na inovação.

Embora se faça esta referência, Ojeda (2017, p. 86-87) destaca que não existe uma norma jurídica específica em vigor na Espanha que trate de cidades inteligentes, pois no caso das normas da UNE não há uma obrigatoriedade de observação. A autora afirma ainda que tais normativas têm tido um valor decisivo e são aprovadas por um comitê estatal (ARN/CTN 178),

\footnotetext{
${ }^{12}$ Os eixos descritos no programa são os seguintes: “(1) facilitar a las ciudades el proceso de transformación hacia una ciudad inteligente; (2): proyectos demostradores de la eficiencia de las tic en la reducción de costes, mejoras en la satisfacción ciudadana y creación de nuevos modelos de negocio; (3) desarrollo y crecimiento de la industria tic; (4) comunicación y difusión del plan nacional de ciudades inteligentes; eje v. seguimiento del plan, actuación trasversal"
} 
tendo um direcionamento exclusivo aos entes públicos locais da Espanha, o que deixa em aberto as questões na perspectiva público-privada.

Assim, na inexistência de uma norma legal para além das normativas, aliadas ao avanço destas práticas pelas comunidades locais na Espanha em decorrência do Plano Nacional, percebe-se a geração de uma série de preocupações jurídicas, entre os quais se destacam: a utilização de dados frente a privacidade dos cidadãos; estruturas de participação nos governos; questões urbanísticas e ambientais, e ainda, de competência em matérias de TICs.

Cada um dos destes temas - e outras tantas matérias afetadas pelas cidades inteligentes - demandariam estudos jurídicos próprios para que fosse compreendido com maior precisão todos os desdobramentos setoriais. Pretende-se aqui somente indicar reflexões gerais, por entender que tais aspectos podem ser vistos como temas de futura preocupação para o Direito no Brasil.

Em matéria de urbanismo, podem ser destacadas duas questões: por um lado, Guitérres (2017, p. 57) destaca que a facilitação ao acesso à informação gerada pelos mecanismos de Smart Cities é indispensável para compreender melhor o que pensam e quais as necessidades das pessoas que vivem o dia a dia da cidade, sendo tal informação, de extrema relevância na definição de algo tão discricionário, quanto é a tomada de decisão sobre o planejamento urbano. Por outro, Ojeda (2017, p. 82) aponta que as novas tecnologias afetam o desenho urbano, e, apesar de tal atribuição claramente pertencer ao âmbito local, tende a exigir um investimento em infraestrutura e manutenção dos serviços em condições, que pode gerar dificuldades de custeio pelas administrações.

A temática ambiental é uma das mais relacionadas as ações previstas para as cidades inteligentes. Neste contexto, Guitérres (2017, p. 58-64) aponta os seguintes desafios centrais para as Políticas Públicas: o controle de qualidade de águas, da poluição sonora e da luz; e a gestão de resíduos, de tráfego e de mobilidade. Todo instrumental de tecnologia pode apresentar-se como importante apoio na concretização de princípios como da precaução e prevenção, pela potencialidade de organizar dados e mensurar riscos e perigos.

Quanto as competências para os TICs, Ojeda (2017, p. 82) destaca que, se for considerada matéria de telecomunicação, competirá ao governo federal espanhol, e, se for tomada em conta a questão urbanística, a realidade passa a ser outra. Com o advento do Plano Nacional, seguiu-se outra regra, que segue sem questionamento judicial: o ente municipal recebe competência ao ter seu projeto aprovado pelo Governo Federal. Uma questão ainda em aberto é se os organismos locais podem requisitar recursos nos editais previstos pela União Europeia (que são frequentes e concedem boas quantias), sem o aceite do governo federal. 
Verifica-se que a experiência da Espanha em cidades inteligentes proporciona uma série de elementos que antecipam alguns debates jurídicos que podem vir a surgir no Brasil. A existência de um plano nacional, com a emissão de uma série de normas técnicas, não supre em definitivo a necessidade de uma lei regulamentadora, mas já dá contornos muito claros do que é e de quais resultados se pretende com as Smart Cities naquele país.

Quanto ao objetivo central deste trabalho, a partir da experiência da Espanha, pode-se avançar com as seguintes reflexões jurídicas para o debate sobre diretrizes jurídicas no Brasil:

Finalidade/Objetivo: as políticas públicas de Smart Cities na Espanha têm como enfoque o desenvolvimento da indústria e um incentivo a ampliação do caráter turístico das comunidades locais. Abre-se o questionamento de quais seriam os critérios que balizariam um programa semelhante no Brasil

Competência: fica confirmado a constatação de que as políticas públicas que evolvem Smart Cities são multidisciplinares, merecendo estudos específicos mais aprofundados, sempre atento ao tema central de cidades inteligentes. Se faz necessário compreender melhor a competência acerca do tema tecnologia no Brasil.

Verifica-se assim, que o estudo da experiência da Espanha acaba por gerar questionamentos que necessitam observação com base na programação do Direito brasileiro, em especial no que diz respeito aos critérios jurídicos para um plano nacional e no entendimento de quem é competente em matéria de tecnologia, tendo como base a Constituição Federal.

\section{As diretrizes jurídicas para políticas públicas de cidades inteligentes no Brasil}

No Brasil, a recente Carta Brasileira sobre Cidades Inteligentes (2021) vem suprir uma lacuna sobre o tema. Embora signifique um avanço, não se trata de norma jurídica e não resolve o cenário de complexidade e ampla contingência de alternativas do tema em âmbito interno, possibilitando iniciativas e decisões de toda ordem. Uma observação da programação do direito vigente no país, que contribua com a construção de diretrizes jurídicas para as Política Públicas, pode iniciar-se pela leitura do texto constitucional, art. $3^{\circ}$, que aponta os objetivos fundamentais da República Federativa do Brasil.

Neste contexto, um programa nacional de Smart Cities, observado na perspectiva jurídica, deve, necessariamente, ter como enfoques finalísticos, a construção de uma sociedade, livre, justa e solidária; a garantia do desenvolvimento nacional; objetivar reduzir as desigualdades regionais, a erradicação da pobreza; promovendo o bem-estar de todos, sem 
quaisquer preconceitos. Deve ainda, em decorrência dos fundamentos elencados nos incisos do art. $1^{\circ}$, ser construído sob os valores da soberania, cidadania, dignidade da pessoa humana, valores sociais do trabalho e da livre iniciativa e do pluralismo político.

Para que indicação destes pressupostos básicos não pareçam questões abertas, de difícil aplicabilidade, distantes da realidade, cabe descrever alguns exemplos, tomando por base assuntos que já foram tangenciados neste trabalho. Assim, ao indicar que as políticas públicas voltadas as cidades inteligentes devem reduzir desigualdades, não se pode aceitar por exemplo, que o exercício da participação por meio de TICs exclua parte da população do país de um determinado processo decisório. Uma política que não aponte alternativas para sanar este efeito, impedindo na prática, que determinada parcela da população não tenha acesso a um determinado serviço, tenderia a aumentar desigualdades regionais, contrariando o texto constitucional.

Outro exemplo pode se dar com base no exercício da Soberania. Boa parte das empresas que apresentam soluções de cidades inteligentes são empresas de atuação global, com inserção mundial, muitas vezes com relações próximas com outros governos. Permitir que utilização de tecnologia dê aos outros países ou grupos econômicos acessos a dados, que permitam interferir em futuras tomadas de decisão de interesse nacional, ou ainda, que coloquem em riscos instituições ou os direitos à privacidade do cidadão brasileiro, também se demostrariam contrários à Constituição, ofendendo a Soberania nacional.

Um exemplo, que evolve cidades inteligentes e que pode ser observado a partir do fundamento da dignidade da pessoa e do objetivo da promoção do bem-estar de todos, e, que acabou sendo levado aos tribunais dos Estados Unidos é um embate entre o Estado de Indiana e a IBM. A controvérsia jurídica é apresentada por Ojeda (2017, p. 89) e diz respeito a opção do Estado de Indiana em substituir os funcionários que tratavam de forma pessoal com os beneficiários de programas sociais básicos, como alimentação e saúde, por equipamentos e softwares que atenderiam os cidadãos via web e telefone móvel. Tal opção gerou graves críticas da população, o que motivou o Estado de Indiana a propor ação contra a IBM por inadimplemento do contrato, e, da IBM perante o Estado de Indiana, solicitando compensação em decorrência dos equipamentos instalados. Na decisão o tribunal definiu compensações recíprocas, em uma espécie de culpa concorrente.

Para nossas reflexões não é a sentença da demanda judicial o que provoca interesse, mas a clareza de que uma política pública de cidade inteligente pode contrariar elementos jurídicos básicos, como o fundamento constitucional da dignidade da pessoa humana e objetivo fundamental de promoção de bem-estar. Trazido para o cenário brasileiro, tal política pública 
escolhida pelo Estado norte americano de Indiana, poderia ser atacada com base nestes valores previstos na $\mathrm{CF} / 1988$ e declarada contrária a programação do direito em uma decisão a ser proferidas pelos tribunais.

Além dos objetivos e fundamentos da República Federativa do Brasil, por estar ligado a temática da ciência, tecnologia e inovação, as políticas públicas de Smart Cities devem ser observadas na perspectiva dos art. 215 a 219-B da CF/1988, que tratam da matéria. Aqui fica clara uma inclinação constitucional de que o Estado pode promover e incentivar temas como as cidades inteligentes. A leitura do art. 215 caput $\mathrm{c} / \mathrm{c}$ o $\S 2^{\circ}$, onde é regrado que "o Estado promoverá e incentivará o desenvolvimento científico, a pesquisa, a capacitação científica e tecnológica e a inovação" e que "a pesquisa tecnológica voltar-se-á preponderantemente para a solução dos problemas brasileiros e para o desenvolvimento do sistema produtivo nacional e regional" deixam claro que políticas públicas de promoção e incentivo, direcionadas para utilização de TIC no contexto das cidades inteligentes - como feito pela Espanha - teriam respaldo nas disposições constitucionais no país.

Boa parte da redação do capítulo, tem origem no teor da Emenda Constitucional n. 85/2015, que traz outros temas para futuros debates jurídicos neste sentido: a possibilidade/incentivo na cooperação público-privada nestas políticas (art. 218, § 6º art. 219A e art. 219-B) e a criação do Sistema Nacional de Ciência, Tecnologia e Inovação (SNCTI), que ainda será criado mediante lei federal (art. 219-B, caput e $\S 1^{\circ}$ ), sendo matéria a ser legislada de maneira concorrente por todos os entes federativos (art. 219-B, $\S 2^{\circ}$ ).

Mesmo sem a criação definitiva do Sistema Nacional de Ciência, Tecnologia e Inovação, o governo brasileiro apresentou o documento denominado Estratégia Nacional de Ciência, Tecnologia e Inovação 2016-2022. Não há um tópico ou capítulo específico sobre cidades inteligentes. De maneira superficial, a proposta traz alguns elementos onde é reconhecida a relevância matéria como uma tendência mundial em ações que tenham por enfoque a redução de riscos e a criação de sistemas urbanos sustentáveis.

O documento trabalha com 12 eixos estratégicos: Aeroespacial e Defesa; Água; Alimentos; Biomas e Bioeconomia; Ciências e Tecnologias Sociais; Clima; Economia e Sociedade Digital; Energia; Minerais Estratégicos; Nuclear; Saúde; Tecnologias Convergentes e Habilitadoras. O termo "cidades inteligentes" somente aparece no detalhando dos eixos 
Economia e Sociedade Digital ${ }^{13}$ e Tecnologias Convergentes e Habilitadoras, todas as vezes ligando o tema a "Internet das Coisas". ${ }^{14}$ (BRASIL, 2017)

Nesta perspectiva, verifica-se que a estratégia nacional de tecnologia 2016-2022 trata de maneira amplamente superficial o tema das cidades inteligentes, com definição de objetivos, eixos, metas, medidas, indicadores e destinação de recursos públicos com esta finalidade. Tal contexto, reforça a necessidade de serem trazidos elementos que direcionem a formação de diretrizes jurídicas como forma de direcionar as políticas públicas no Brasil, onde o tema tem grande variação. Importante ressaltar que ao final do ano de 2020 intensificaram-se os debates nacionais sobre o tema, com a publicação recente da Carta Brasileira sobre Cidades Inteligentes, documento que tende a nortear as ações sobre o assunto no país e servir de base para normativas jurídicas.

Desta forma, a observação da perspectiva constitucional e das políticas nacionais acerca do tema, apontam para os seguintes elementos:

Finalidade/Objetivo: as políticas públicas de Smart Cities devem convergir com os Objetivos Fundamentais da República Federativa do Brasil. No caso de políticas públicas específicas de tecnologia, devem voltar-se a solução dos problemas brasileiros e incentivo a economia setorial. Meios a serem observados: devem, ao menos, atender os fundamentos da República Federativa do Brasil.

Competência: as políticas públicas de tecnologia em Smart Cities devem ser promovidas e incentivadas pelo Estado e não existindo um dever expresso, que obrigue a adotar esta opção. A competência material em proporcionar os meios de acesso para a tecnologia, por força do art. 23, V da CF é comum da União, Estados, Municípios e Distrito Federal. Há uma competência concorrente da União, Estados e Distrito Federal para legislar sobre a matéria, com base no art. 24, IX. Há uma competência legislativa concorrente entre todos os entes nas definições do sistema nacional, com base no art. art. 219-B, $\S 2^{\circ}$ (SNCTI).

\footnotetext{
13 “As aplicações da Internet das Coisas em benefício da sociedade são diversas. cidades inteligentes com controle eficiente do tráfego automotivo e disponibilidade de informações públicas a qualquer cidadão; carros conectados que podem atuar de forma ativa na prevenção de acidentes e até mesmo se conduzirem de forma autônoma; monitoramento ambiental, viabilizando melhor controle da qualidade do ar e da água, além de tornar possível o gerenciamento de catástrofes em áreas de risco e melhoria de processos de produção por meio do uso de redes de sensores em fábricas conectadas". "Para coordenar esforços de PD\&I e adoção da Internet das Coisas, foi estabelecida a Câmara IoT, órgão multissetorial cujo objetivo principal é elaborar um plano estratégico para o desenvolvimento e a implementação de soluções de IoT em todos os possíveis setores. Podemos destacar atualmente ações de manufatura avançada, agropecuária de precisão, sistemas de monitoramento de transportes e logística e soluções voltadas para cidades inteligentes. Em meio a essas iniciativas, é necessário aprimorar a capacidade do País em dominar a cadeia produtiva de microeletrônica e dispositivos, de forma a garantir a autonomia tecnológica brasileira no setor".

14 “'Outra tecnologia habilitadora que podemos citar são as inúmeras soluções voltadas para as cidades inteligentes. Atualmente, questões como segurança pública, mobilidade urbana e desperdício de recursos (água, esgoto e energia) estão cada dia mais sendo solucionadas com a aplicação de tecnologias de Internet das Coisas".
} 
Feitas estas ponderações, passa-se as considerações finais articuladas, onde serão apresentadas algumas reflexões finais para o avanço do tema das cidades inteligentes no país, em especial, como contribuição para o desenvolvimento de novos estudos e regulamentações da matéria.

\section{Considerações finais}

A partir da observação dos debates internacionais, como ONU e BID e das experiências da Espanha no tema cidades inteligentes, confrontados com a programação do sistema do direito no Brasil, podem ser apresentadas as considerações:

- A abordagem do tema cidades inteligentes confirma que sua ação governamental envolve tema complexo, devendo as políticas públicas desenvolvidas neste contexto, serem pensadas de maneira aberta, de forma a atender a toda contingência e complexidade que envolve o tema. Tal atuação, não se configura como uma simples utilização de tecnologia, mas de um uso que traga avanços socioeconômicos para a população, servindo como parâmetros jurídicos, o conceito interesse público e os princípios da administração pública, e, em se tratando de política urbana, os objetivos constitucionais e as diretrizes previstas no Estatuto da Cidade.

- Embora o tema Cidade Inteligente deva ser observado como central, ele envolve uma série de políticas setoriais, como urbanismo, tecnologia, transporte e mobilidade, meio ambiente, acesso à informação, prestação de diversos serviços públicos, entre outros. Assim, não tende a lograr êxito políticas públicas que definam as competências de uma maneira isolada, sendo de grande utilidade que os estudos, iniciativas e regulamentações estejam atentos ao conceito de policompetencia, apto por garantir uma maior efetividade na ação estatal voltada para Smart Cities.

- Já há debates jurídicos mais avançados no Brasil quanto a utilização de TICs na participação social, entretanto, outros temas latentes, como segurança de dados, utilização de informações com enfoque no planejamento urbano, as diversas questões ambientais, novas alternativas de transporte público, entre outros, ainda são incipientes e necessitam ser observados pelo Direito.

- A inexistência de uma normativa, somada ao cenário de competência material comum e legislativa concorrente em matéria de tecnologia, tende a gerar uma proliferação de modelos, sem cooperação, sem formação de uma identidade e sem estandardização que facilite o acesso aos mecanismos de Cidade Inteligente, aos mais de 5 mil Municípios. A construção de um 
Plano Nacional deve ter em conta os aspectos jurídicos dos objetivos e fundamentos da República Federativa do Brasil, assim como a Carta Brasileira sobre Cidades Inteligentes.

Como resposta ao problema, entende-se que fora confirmada a hipótese apresentada, vez que os debates da ONU e BID, assim como a experiência da Espanha, trazem consigo elementos que auxiliam nos avanços dos estudos, contribuindo com a definição de diretrizes jurídicas quanto a competência, finalidade e os meios a serem observados na produção de Políticas Públicas de Smart Cities para o Brasil.

\section{Referências}

BORJA, Jordi; MUXÍ, Zaida. Urbanismo en el siglo XXI: Bilbao, Madrid, Valencia y Barcelona. Barcelona: ETSAB, 2009.

BOUSKELA, Maurício; CASSEB, Marcia. Caminho para as Smart Cities: Da Gestão Tradicional para a Cidade Inteligente. Washington, D.C: BID, 2016.

BRASIL. Carta Brasileira sobre Cidades Inteligentes. Disponível em https://bityli.com/zxauN. Acesso em 20.04.2021.

BRASIL. Constituição Federal. Disponível em https://bit.ly/1bIJ9XW. Acesso em 30.12.2018.

BRASIL. Estatuto da Cidade. Lei 10.257 de 10 de julho de 2001. Regulamenta os arts. 182 e 183 da Constituição Federal, estabelece diretrizes gerais da política urbana e dá outras providências. Disponível em https://bit.ly/106qbRX. Acesso em: 31 dez. 2018.

BRASIL. Estratégia Nacional de Ciência, Tecnologia e Inovação 2016-2022. Brasília: Ministério da Ciência, Tecnologia, Inovações e Comunicações, 2017.

BRASIL. Lei Geral de Proteção de Dados (LGPD). Lei 13.709 de 14 de agosto de 2018. Disponível em https://bityli.com/HKFy5. Acesso em: 20 abr. 2021.

BRASIL. Política Nacional de Mobilidade Urbana. Lei 12.587 de 03 de janeiro de 2012. Institui as diretrizes da Política Nacional de Mobilidade Urbana. Disponível em https://bit.ly/2VtcmT7. Acesso em 03.01.2019.

ESPANHA. Plan Nacional de Ciudades Inteligentes. Madrid: Gobierno de España, 2015. Disponível em https://bit.ly/2d00Wkb. Acesso em: 29 dez. 2018.

ESPANHA. UNE 178201:2016. Ciudades Inteligentes. Definición, atribuitos e requisitos. Disponível em https://bit.ly/2VqQtnK. Acesso em: 29 dez. 2018.

FONSECA, Raphael Di Tommaso Lugarinho. Autodeterminação Informativa e Proteção de Dados Pessoais enquanto Direitos Fundamentais à Luz da ADI 6.387. Trabalho de Conclusão de Curso (Pós Graduação Latu Sensu), Fundação Escola Superior do Ministério Público - RS, 2021. 
GARCÍA DE ENTERRIA, Eduardo. FERNANDEZ, Tomáz-Ramón. Curso de Derecho Administrativo I. $16^{\mathrm{a}}$ ed. Pamplona: Civitas, 2013.

GUIMARÃES, Patrícia Borba Vilar; ARAÚJO, Douglas da Silva. O direito à cidade no contexto das smarts cities: o uso das tic's na promoção do planejamento urbano inclusivo no Brasil. Revista de Direito da Cidade, v. 10, n. 3, p. 1788-1812, ago. 2018. Disponível em: https://doi.org/10.12957/rdc.2018.33226.

GUIMARÃES, Patrícia Borba Vilar; XAVIER, Yanko Marcius de Alencar. Smart cities e direito: conceitos e parâmetros de investigação da governança urbana contemporânea. Revista de Direito da Cidade, v. 8, n. 4, p. 1362-1380, dez. 2016. Disponível em:

https://doi.org/10.12957/rdc.2016.26871.

GUITÉRREZ, Rubén Martinez. El Impacto de las Smart Cities en La Tuetela Ambiental y en la Planificación Urbana. p. 53-73. In MAÑAS, José Luis Piñar; OJEDA, Magdalena, Suárez. Smart Cities: Dereho y Técnica para Una Ciudad Más Habitable. Reus: Madrid, 2017.

LEAL, Rogério Gesta. Impactos econômicos e sociais das decisões judiciais: aspectos introdutórios. Brasília: ENFAM, 2010.

LUHMANN, Niklas. O Direito da Sociedade. São Paulo: Martins Fontes, 2016.

MAÑAS, José Luis Piñar. Derecho, Técnica e Innovación en Las Llamadas Ciudades Inteligentes: Privacidad y Gobierno Abierto. p. 11-33 In MAÑAS, José Luis Piñar; OJEDA, Magdalena, Suárez. Smart Cities: Dereho y Técnica para Una Ciudad Más Habitable. Reus: Madrid, 2017.

MARQUINA, Avelino Brito. Prólogo. p. 7-10. In MAÑAS, José Luis Piñar; OJEDA, Magdalena, Suárez. Smart Cities: Dereho y Técnica para Una Ciudad Más Habitable. Reus: Madrid, 2017.

MATEO, Ramón Martín; SANCHEZ, Juan José Díez Sánchez. Manual de Derecho Administrativo. 29a ed. Pamplona: Aranzadi, 2012.

OJEDA, Magdalena, Suárez. Smart Cities: Un Nuevo reto para El Derecho Público. p. 73-92 In MAÑAS, José Luis Piñar; OJEDA, Magdalena, Suárez. Smart Cities: Dereho y Técnica para Una Ciudad Más Habitable. Reus: Madrid, 2017.

ONU. Documentos Temáticos Habitat III: 21-Cidades Inteligentes. Nova Iorque: ONU, 2015. Disponível em https://bit.ly/2EZ8Av3. Acesso em 31.12.2018.

ONU. Nova Agenda Urbana. Quito: ONU, 2016. Disponível em https://bit.ly/2LGSCab. Acesso em: 31 dez. 2018.

RECK, Janriê Rodrigues. Observação Pragmático-Sistêmica da Competência como Decisão Coordenadora de Ações In BITENCOURT, Caroline Muller; RECK, Janriê Rodrigues. Políticas Públicas e Matriz Pragmático-sistêmica: os novos caminhos científicos do Direito Administrativo no Brasil. Santa Cruz do Sul: Essere Nel Mondo, 2018. 
RECK, Janriê Rodrigues. Observação Pragmático-Sistêmica do Conceito de Serviço Público. 2009. Tese (Doutorado em Direito), Universidade do Vale dos Sinos, 2009.

RECK, Janriê Rodrigues; BITENCOURT. Caroline Müller. Categorias de análise de políticas públicas e gestão complexa e sistêmica de políticas públicas. A\&C - Revista de Direito Administrativo \& Constitucional, Belo Horizonte, ano 16, n. 66, p. 131-151, out./dez, 2016.

RECK, Janriê Rodrigues; VANIN, Fábio Scopel. O direito e as cidades inteligentes: desafios e possibilidades na construção de políticas públicas de planejamento, gestão e disciplina urbanística. Revista de Direito da Cidade, v. 12, n. 1, p. 464-492, maio 2020. Disponível em: https://doi.org/10.12957/rdc.2020.39618.

VANIN, Fábio Scopel. Direito e Política Urbana: Gestão Municipal para a Sustentabilidade. Caxias do Sul: Educs, 2015.

VANIN, Fábio Scopel. A política pública de intervenção urbanística e o regime jurídico dos grandes projetos urbanos: os limites e as possibilidades de inovação no exercício da competência municipal. Tese (Doutorado em Direito), Programa de Pós-Graduação em Direito - Mestrado e Doutorado. Universidade de Santa Cruz do Sul, 2020. Acesso em: http://hdl.handle.net/11624/2909. 